\title{
Effect of different prey species on the life history parameters of Chrysoperla sinica (Neuroptera: Chrysopidae)
}

\author{
Niaz Hussain KHUHRO, Hongyin CHEN*, Ying ZHANG, Lisheng ZHANG and Mengeing WANG
}

Key Laboratory of Integrated Pest Management in Crops, Ministry of Agriculture, Institute of Plant Protection, Chinese Academy of Agricultural Sciences, and USDA-ARS Sino-American Biological Control Laboratory, Beijing, 100081, P.R. China; e-mail: khuhroniaz@gmail.com

Key words. Neuroptera, Chrysopidae, Chrysoperla sinica, prey species, pre-imaginal development, survival, adult longevity, fecundity

\begin{abstract}
Results of studies on prey suitability for generalist predators are important for efficient mass rearing and implementing Integrated Pest Management Programmes (IPM). The green lacewing, Chrysoperla sinica (Tjeder), is a polyphagous natural enemy attacking several pests on various crops in China. We investigated the effect of feeding it different species of prey on its preimaginal development, survival, adult longevity and fecundity under laboratory conditions. The prey species tested were nymphs of Aphis glycines Matsumura, cotton aphid Aphis gossypii Glover, peach aphid Myzus persicae Sulzer, corn aphid Rhopalosiphum maidis Fitch and cowpea aphid Aphis craccivora Koch, and eggs of the rice grain moth, Corcyra cephalonica Stainin. None of these species of prey affected the pre-imaginal survival or percentage survival of the eggs of the predator. However, eggs of $C$. cephalonica and nymphs of M. persicae and A. glycines were the best of the prey species tested, in that when fed on these species the preimaginal developmental period of $C$. sinica was shorter and its adult longevity, fecundity and percentage survival greater than when fed the other species of prey. In contrast, when fed nymphs of $A$. craccivora the pre-imaginal development period was longer, adult longevity shorter and fecundity lower. These findings could be helpful in defining more optimum conditions for the mass rearing of C. sinica for use in integrated pest management (IPM) programmes for various crops.
\end{abstract}

\section{INTRODUCTION}

Chrysopids feed on various aphid species, including Aphis glycines Matsumura (Ragsdale et al., 2011), Myzus persicae Sulzer (Pappas et al., 2007), Diuraphis noxia Mordvilko (Messina \& Sorenson, 2001), Aphis gossypii Glover (Liu \& Chen, 2001), Lipaphis erysimi Kalt. (Kumar \& Singh, 2001), Rhopalosiphum maidis Fitch (El-Serafi et al., 2000), Aphis craccivora Koch (Saminathan et al., 1999) and Monellia caryella Fitch (Liao et al., 1985). They also feed on the eggs of Lepidoptera such as Corcyra cephalonica Stainin (Bansod \& Sarode, 2000), Anagasta kuehniella Zeller (Zheng et al., 1993) and Sitotroga cerealella Olivier (López-Arroyo et al., 1999). The green lacewing, Chrysoperla sinica (Tjeder) (Neuroptera: Chrysopidae), is distributed throughout China (Xu et al., 1999) and a key predator of many important agricultural pests (notably aphids, leafhoppers, thrips, mites and Lepidoptera) (Principi \& Canard, 1984; Ding \& Chen, 1986; Zheng et al., 1993; Atlihan et al., 2004; Wang \& He, 2006; Ragsdale et al., 2011). However, the adults of $C$. sinica are not predators and feed mostly on plant nectar, honeydew and pollen (Villenave et al., 2006; Li et al., 2008). The larvae of $C$. sinica forage actively and are voracious predators of various species of prey (Xu et al., 1999; Duelli, 2001) and frequently used in augmentative and inundative biological control of agricultural pests (Zhou et al., 1991; Senior \& McEwen, 2001). In order to optimize the conditions used by biocontrol companies to rear $C$. sinica and achieve a more cost effective method of rearing various other species of prey and artificial diets have been used (Lee \& Lee 2005; Uddin et al., 2005; Kazemi \& Mehrnejad, 2011). However, mass rearing techniques are still relatively inefficient. Therefore, it is important for the successful development of pest management programs that utilize $C$. sinica as a biocontrol agent to identify alternative high quality prey/food.

The relationship between the quantity of food eaten and fecundity for several species of chrysopids is well documented (Hagen \& Tassan, 1970; Andow, 1990; Tauber et al., 2000). However, there are no studies on the effect of different prey species on the biology, life table parameters, fecundity and adult longevity of $C$. sinica, despite its importance as a predator of aphid pests in China. For example, requirements for the pre-imaginal development and reproduction of adults of $C$. sinica have not been studied. The importance of the nutritional quality of the prey for this predator is also unknown.

The aim of the present study was to evaluate five species of aphid (A. glycines, A. gossypii, M. persicae, $R$. maidis and $A$. craccivora) and the eggs of $C$. cephalonica as food for $C$. sinica in terms of survival, development and reproduction under laboratory conditions. Such information would be helpful for optimizing the mass rearing of $C$. sinica and for understanding its population dynamics in the field in the presence/absence of the various species of prey tested. Ultimately, the results may

\footnotetext{
* Corresponding author; e-mail: hongyinc@163.com
} 
also help in designing integrated pest management (IPM) programs involving the use of $C$. sinica as a biocontrol agent of pests on various crops.

\section{MATERIAL AND METHODS}

\section{Insects}

Adults of $C$. sinica were collected from the field at Langfang Experimental Station, Chinese Academy of Agricultural Sciences, Hebei Province, P.R. China $\left(39^{\circ} 53^{\prime} \mathrm{N}, 116^{\circ} 70^{\prime} \mathrm{E}\right)$ in August 2008 and maintained in the laboratory without any further introduction of field-collected lacewings. Before the experiment 11-12 generations of $C$. sinica were reared in the laboratory. The experimental $C$. sinica adults were obtained from this colony. Adults were maintained in cylindrical glass jars $(18 \mathrm{~cm}$ in diameter and $25 \mathrm{~cm}$ high). They had access to water and the artificial diet described by Zhou et al. (1981). Larvae were reared in Petri dishes ( $9 \mathrm{~cm}$ diameter, $1 \mathrm{~cm}$ high) on A. glycines, which were reared on soybean plants grown hydroponically (Zhang et al., 2009). Rearing conditions for stock cultures of chrysopids were $25 \pm 2{ }^{\circ} \mathrm{C}$ and a photoperiod of $16 \mathrm{~L}: 8 \mathrm{D}$. The voucher specimens of the insects used in this study are deposited in the Key Laboratory for Biological Control, Ministry of Agriculture, Institute of Plant Protection, and Chinese Academy of Agricultural Sciences, Beijing, P.R. China.

Five aphid species (A. glycines, A. gossypii, R. maidis, $M$. persicae and A. craccivora) were provided as prey for $C$. sinica. In addition, the eggs of $C$. cephalonica were also tested. Aphis glycines and M. persicae were reared on soybean (Glycine max) and Brassica chinensis plants, respectively. The soybean and $B$. chinensis plants were grown in a greenhouse in plastic pots $(30$ $\times 10 \times 5 \mathrm{~cm}$ and $10 \times 7 \times 5 \mathrm{~cm}$, respectively) at $24 \pm 3^{\circ} \mathrm{C}$ and a photoperiod of 16L : 8D. Cowpea (Vigna unguiculata) and maize (Zea mays) plants were planted early in July 2010 outside the greenhouse and were used as trap plants for collecting $A$. craccivora and R. maidis, respectively. Aphis gossypii were collected in a cotton field at Langfang Experimental Station and used directly in the experiments. Eggs of C. cephalonica were collected from a laboratory colony reared on wheat flour.

\section{Suitability of different species of prey as food for the imma- ture stages of $C$. sinica}

To investigate the suitability of prey as food for the preimaginal development of $C$. sinica eggs were collected from the mass-reared laboratory culture and kept in small tubes $(1 \mathrm{~cm}$ diameter and $4 \mathrm{~cm}$ long) at $25 \pm 1{ }^{\circ} \mathrm{C}$, relative humidity (RH) of $65 \pm 10 \%$ and a photoperiod of 16L : 8D. Eggs were checked every $3-4 \mathrm{~h}$ and newly emerged larvae were transferred singly with a camel hair brush to a plastic Petri dish $(9 \mathrm{~cm}$ diameter, $1.5 \mathrm{~cm}$ high). To maintain adequate ventilation inside the Petri dish, a 3-cm-diameter hole in the lid was covered with screen cleaning cloth. To prevent larvae from escaping Petri dishes were wrapped in Parafilm ${ }^{\mathrm{TM}}$ after inspection. Third- and fourthinstar nymphs of each aphid species were supplied daily to the chrysopid larvae (ad libitum 15-200 aphids according to larval age) throughout their larval development. In the case of $C$. cephalonica eggs, fresh eggs were supplied daily to larvae (ad libitum 50-250 eggs according to larval age). The survival and development of the lacewing larvae were recorded twice a day at 09:00 and 18:00. All the experiments were conducted at $25 \pm$ $1{ }^{\circ} \mathrm{C}, 65 \pm 10 \% \mathrm{RH}$ and a photoperiod of $16 \mathrm{~L}: 8 \mathrm{D}$. In each treatment, 50-60 newly hatched larvae were tested.

\section{Effects of feeding on different species of prey on the adult longevity and fecundity of $\boldsymbol{C}$. sinica}

Adults of $C$. sinica were examined under a dissecting microscope on the day of emergence and sorted according to sex.
Single pairs were confined in cylindrical glass jars $(10 \mathrm{~cm}$ in diameter and $20 \mathrm{~cm}$ high) and supplied with the artificial diet described above for colony maintenance. One end of the cylindrical glass jar was covered with absorbent cloth. Due to the height of the glass jars, cotton wool wrapped in absorbent cloth was placed at the bottom of each of the jars in order to facilitate the collection of eggs from the bottom of the jar. The number of eggs laid, female survival and longevity was recorded daily. Egg viability was monitored by collecting 10 eggs per female per day throughout a female's life and keeping them in a tube (1 $\mathrm{cm}$ diameter, $4 \mathrm{~cm}$ long). The ends of the tubes were closed with cotton wool. These eggs were kept at the same temperature and photoperiod as the adults. The number of hatched and unhatched eggs was recorded every third or fourth day (incubation period).

\section{Data analysis}

Analysis of variance (ANOVA) was used to compare the effect of prey species on developmental time of $C$. sinica. $\log$ transformation of data was used to minimise variances and means were compared using Duncan's multiple range test $(P<$ $0.05)$ using the procedure in SAS (SAS Institute, 1988). The fecundity and longevity data were analyzed using One-way Analysis of Variance (ANOVA) and Duncan's multiple range test $(P<0.05)$ and percentage data (preimaginal survival, hatching) was analyzed using Chi-Square tests. A t-test was used to compare the total development times of females and males. Prior to analysis, we ensured that all data met assumptions of normality and homoscedasticity.

\section{RESULTS}

\section{Suitability of different species of prey as food for the immature stages of $\boldsymbol{C}$. sinica}

The duration of pre-imaginal development in $C$. sinica was significantly affected by prey species and sex of the lacewing $(\mathrm{F}=71.6500 ; \mathrm{df}=5226 ; P<0.05$ and $(\mathrm{F}=$ 48.7800; df $=1237 ; P<0.05$, respectively). The duration of each pre-imaginal stage and mean total duration of development of both females and males were significantly affected by all the species of prey tested ( $1^{\text {st }}$ instar larva: $\mathrm{F}=35.0280 ; \mathrm{df}=5112 ; P<0.05 ; 2^{\text {nd }}$ instar larva: $\mathrm{F}$ $=30.6040 ; \mathrm{df}=5112 ; P<0.05 ; 3^{\text {rd }}$ instar larva: $\mathrm{F}=$ 19.6030; df $=5112 ; P<0.05$; pupa: $\mathrm{F}=16.0550$; $\mathrm{df}=$ 5112; $P<0.05$; overall immature development: $\mathrm{F}=$ 54.9680; df $=5112 ; P<0.05$ and $1^{\text {st }}$ instar larva: $\mathrm{F}=$ 40.8970, df $=5124 ; P<0.05 ; 2^{\text {nd }}$ instar larva: $\mathrm{F}=$ $22.2360 ; \mathrm{df}=5124 ; P<0.05 ; 3^{\text {rd }}$ instar larva: $\mathrm{F}=$ 27.2310; $\mathrm{df}=5124 ; P<0.05$; pupa: $\mathrm{F}=48.6010$; $\mathrm{df}=$ 5,124; $P<0.5$; total immature development: $\mathrm{F}=$ 102.1160; $\mathrm{df}=5124 ; P<0.5$, respectively).

Larval developmental time did not differ significantly between males and females (Table 1) except for the $2^{\text {nd }}$ instar larvae reared on $A$. glycines, $1^{\text {st }}$ instar on $M$. persicae, and all three instars reared on $R$. maidis $\left(1^{\text {st }}\right.$ to $3^{\text {rd }}$ instar larvae $)(\mathrm{t}=2.4124, \mathrm{df}=38, P<0.05 ; \mathrm{t}=2.6816, \mathrm{df}$ $=37, P<0.05 ; \mathrm{t}=5.9074$, df $=27.309, P<0.05 ; \mathrm{t}=$ 2.2876, $\mathrm{df}=40, P<0.05$ and $\mathrm{t}=4.3892, \mathrm{df}=27.309, P<$ 0.05 , respectively). However, the mean pupal developmental period of males and females differed significantly except when the larvae were reared on A. glycines $(\mathrm{t}=$ 1.5184 , df $=38, P=0.1372$ ). Similarly, the mean total pre-imaginal developmental period of males and females was significantly different in all the treatments (A. glyci- 
TABLE 1. Mean developmental time of pre-imaginal developmental stages of $C$. sinica reared on different species of prey.

\begin{tabular}{|c|c|c|c|c|c|c|}
\hline \multirow{2}{*}{ Prey } & \multirow{2}{*}{$n^{1}$} & \multicolumn{5}{|c|}{ Development time (days) } \\
\hline & & $1^{\text {st }}$ instar & $2^{\text {nd }}$ instar & $3^{\text {rd }}$ instar & Pupa & Total pre-imaginal \\
\hline \multicolumn{7}{|l|}{ Females } \\
\hline A. glycine & 19 & $4.18 \pm 0.07 b$ & $3.13 \pm 0.06 \mathrm{~b}$ & $3.37 \pm 0.07 \mathrm{c}$ & $10.03 \pm 0.20 \mathrm{~b}$ & $20.71 \pm 0.25 b$ \\
\hline M. persicae & 19 & $4.18 \pm 0.09 b$ & $2.89 \pm 0.05 \mathrm{c}$ & $3.21 \pm 0.07 \mathrm{~cd}$ & $10.24 \pm 0.09 b$ & $20.53 \pm 0.18 b$ \\
\hline A. craccivora & 17 & $5.62 \pm 0.11 \mathrm{a}$ & $3.85 \pm 0.06 \mathrm{a}$ & $4.09 \pm 0.08 \mathrm{a}$ & $10.88 \pm 0.13 a$ & $24.44 \pm 0.20 \mathrm{a}$ \\
\hline C. cephalonica & 19 & $4.26 \pm 0.13 b$ & $2.95 \pm 0.09 \mathrm{c}$ & $3.84 \pm 0.13 b$ & $10.03 \pm 0.11 b$ & $21.08 \pm 0.30 \mathrm{~b}$ \\
\hline R. maidis & 17 & $4.13 \pm 0.08 b$ & $2.82 \pm 0.07 \mathrm{~cd}$ & $3.42 \pm 0.07 \mathrm{c}$ & $9.26 \pm 0.17 \mathrm{c}$ & $19.63 \pm 0.26 \mathrm{c}$ \\
\hline A. gossypii & 20 & $3.8 \pm 0.06 \mathrm{c}$ & $2.70 \pm 0.06 \mathrm{~d}$ & $3.10 \pm 0.08 \mathrm{~d}$ & $9.55 \pm 0.13 \mathrm{c}$ & $19.15 \pm 0.20 \mathrm{c}$ \\
\hline \multicolumn{7}{|l|}{ Males } \\
\hline A. glycine & 21 & $4.14 \pm 0.05 b$ & $2.93 \pm 0.05 b$ & $3.21 \pm 0.07 b c$ & $9.67 \pm 0.12 b$ & $19.95 \pm 0.17 b$ \\
\hline M. persicae & 20 & $3.88 \pm 0.07 \mathrm{c}$ & $2.88 \pm 0.05 b$ & $3.3 \pm 0.08 b$ & $9.65 \pm 0.08 b$ & $19.65 \pm 0.18 b$ \\
\hline A. craccivora & 19 & $5.18 \pm 0.15 \mathrm{a}$ & $3.53 \pm 0.08 \mathrm{a}$ & $3.76 \pm 0.07 \mathrm{a}$ & $10.37 \pm 0.06 \mathrm{a}$ & $22.84 \pm 0.20 \mathrm{a}$ \\
\hline C. cephalonica & 22 & $3.91 \pm 0.12 \mathrm{c}$ & $2.82 \pm 0.08 b c$ & $3.59 \pm 0.05 \mathrm{a}$ & $9.48 \pm 0.06 b$ & $19.80 \pm 0.18 b$ \\
\hline R. maidis & 23 & $3.59 \pm 0.04 \mathrm{~d}$ & $2.63 \pm 0.05 \mathrm{~d}$ & $3.09 \pm 0.04 \mathrm{c}$ & $8.78 \pm 0.07 \mathrm{~d}$ & $18.09 \pm 0.13 c$ \\
\hline A. gossypii & 20 & $3.65 \pm 0.05 \mathrm{~d}$ & $2.7 \pm 0.06 \mathrm{~cd}$ & $2.9 \pm 0.05 \mathrm{~d}$ & $9.10 \pm 0.05 c$ & $18.35 \pm 0.10 \mathrm{c}$ \\
\hline
\end{tabular}

Notes: ${ }^{1} n=$ number of individuals tested; ${ }^{2}$ means in the same column followed by different letters are significantly different (Duncan's multiple range test, $P<0.05)$. The values are means $\pm \mathrm{SE}$.

nes: $\mathrm{t}=2.5666, \mathrm{df}=38, P<0.05 ;$ M. persicae: $\mathrm{t}=$ $3.4219, \mathrm{df}=37, P<0.05 ;$ A craccivora: $\mathrm{t}=5.6570, \mathrm{df}=$ 34, $P<0.05$; eggs of $C$. cephalonica: $\mathrm{t}=3.8158, \mathrm{df}=39$, $P<0.05 ; R$. maidis: $\mathrm{t}=5.5698, \mathrm{df}=28, P<0.05$; and $A$. gossypii: $\mathrm{t}=3.7193, \mathrm{df}=28, P<0.05)$. Our results show that the mean total pre-imaginal developmental period of males and females was significantly different when lacewing larvae were supplied with $A$. craccivora nymphs $\left(1^{\text {st }}\right.$ instar larvae: $\mathrm{t}=2.4684$, $\mathrm{df}=34, P<0.05 ; 2^{\text {nd }}$ instar larvae: $\mathrm{t}=3.2181$, $\mathrm{df}=34, P<0.05 ; 3^{\text {rd }}$ instar larvae: $\mathrm{t}=$ 3.1409 , df $=34, P<0.05$; pupae: $\mathrm{t}=3.6488$, df $=24, P<$ 0.05 , respectively). In this study, the effect of the different prey species tested on the developmental rates of C. sinica larvae was significant.

Moreover, our results suggest that the pre-imaginal survival of $C$. sinica fed on the different prey species did not differ significantly $\left(\chi^{2}=10.7878, \mathrm{df}=5\right)$.

\section{Effect of feeding on different species of prey on the adult longevity and fecundity of $\boldsymbol{C}$. sinica}

Adult longevity $(\mathrm{F}=8.4440, \mathrm{df}=589, P<0.5)$ and fecundity $(\mathrm{F}=30.0160, \mathrm{df}=5.89, P<0.5)$ of $C$. sinica were significantly affected by the species of prey (Table $2)$. Maximum female longevity ( $\sim 58$ days) was recorded when the larvae were fed on eggs of $C$. cephalonica; the minimum ( $\sim 5$ days) when fed on nymphs of $A$. craccivora. Moreover, maximum fecundity ( 551 eggs) was also recorded when larvae were fed on eggs of C. cephalonica and the lowest ( 242 eggs) when they were fed on nymphs of $A$. craccivora.

The age-specific oviposition rates and survival of $C$. sinica supplied with different prey species are shown in Fig. 1. The percentage of eggs that hatched was high and in the range of approximately $89-95 \%$ and did not differ significantly between treatments $\left(\chi^{2}=98.8998, \mathrm{df}=5\right)$.

\section{DISCUSSION}

The larvae of $C$. sinica feed on a variety of soft-bodied insects (Tauber \& Tauber, 1983; Ding \& Chen, 1986; Zheng et al., 1993; Rao et al., 2003; Rajabaskar, 2007) and are considered to be key predators of many agriculturally important pests (Principi \& Canard, 1984; Ragsdale et al., 2011). It is widely reported that unsuitable food can extend the pre-imaginal development of chrysopids and decrease the survival, fecundity and longevity of the adults (Principi \& Canard, 1984; Obrycki et al., 1989; Zheng et al., 1993). In this study we evaluated

TABLE 2. Larval survival, mean female adult longevity and mean total fecundity of $C$. sinica reared on different species of prey.

\begin{tabular}{lcccccc}
\hline Prey species & $n^{1}$ & $\begin{array}{c}\text { Pre-imaginal } \\
\text { survival (\%) }\end{array}$ & $\begin{array}{c}\text { Number } \\
\text { of females }^{3}\end{array}$ & $\begin{array}{c}\text { Hatchability } \\
(\%)\end{array}$ & $\begin{array}{c}\text { Female longevity } \\
\text { (days) }\end{array}$ & $\begin{array}{c}\text { Female fecundity } \\
\text { (eggs/female) }\end{array}$ \\
\hline A. glycine & 60 & 66.7 & 19 & 92.40 & $53.43 \pm 2.18 \mathrm{ab}$ & $488.87 \pm 21.42 \mathrm{ab}$ \\
M. persicae & 50 & 78 & 19 & 89.83 & $52.43 \pm 2.05 \mathrm{ab}$ & $482.53 \pm 26.00 \mathrm{ab}$ \\
A. gossypii & 50 & 80 & 20 & 94.35 & $52.33 \pm 2.22 \mathrm{~b}$ & $413.07 \pm 11.63 \mathrm{~b}$ \\
C. cephalonica & 50 & 82 & 19 & 94.70 & $58.67 \pm 2.00 \mathrm{a}$ & $551.93 \pm 28.70 \mathrm{a}$ \\
R. maidis & 60 & 66.7 & 17 & 95.26 & $51.67 \pm 1.55 \mathrm{~b}$ & $421.33 \pm 16.35 \mathrm{~b}$ \\
A. craccivora & 60 & 60 & 17 & 90.13 & $45.29 \pm 1.76 \mathrm{c}$ & $242.53 \pm 17.70 \mathrm{c}$ \\
\hline
\end{tabular}

Notes: ${ }^{1} n=$ initial number of newly hatched larvae tested; ${ }^{2}$ pre-imaginal survival $=100 \times$ (total number of emerging adults) / (initial number of newly hatched larvae tested); ${ }^{3}$ number of females tested; ${ }^{4}$ means in a column followed by different letters are significantly different (Duncan's multiple range test, $P<0.05$ ). The values are means $\pm \mathrm{SE}$. 

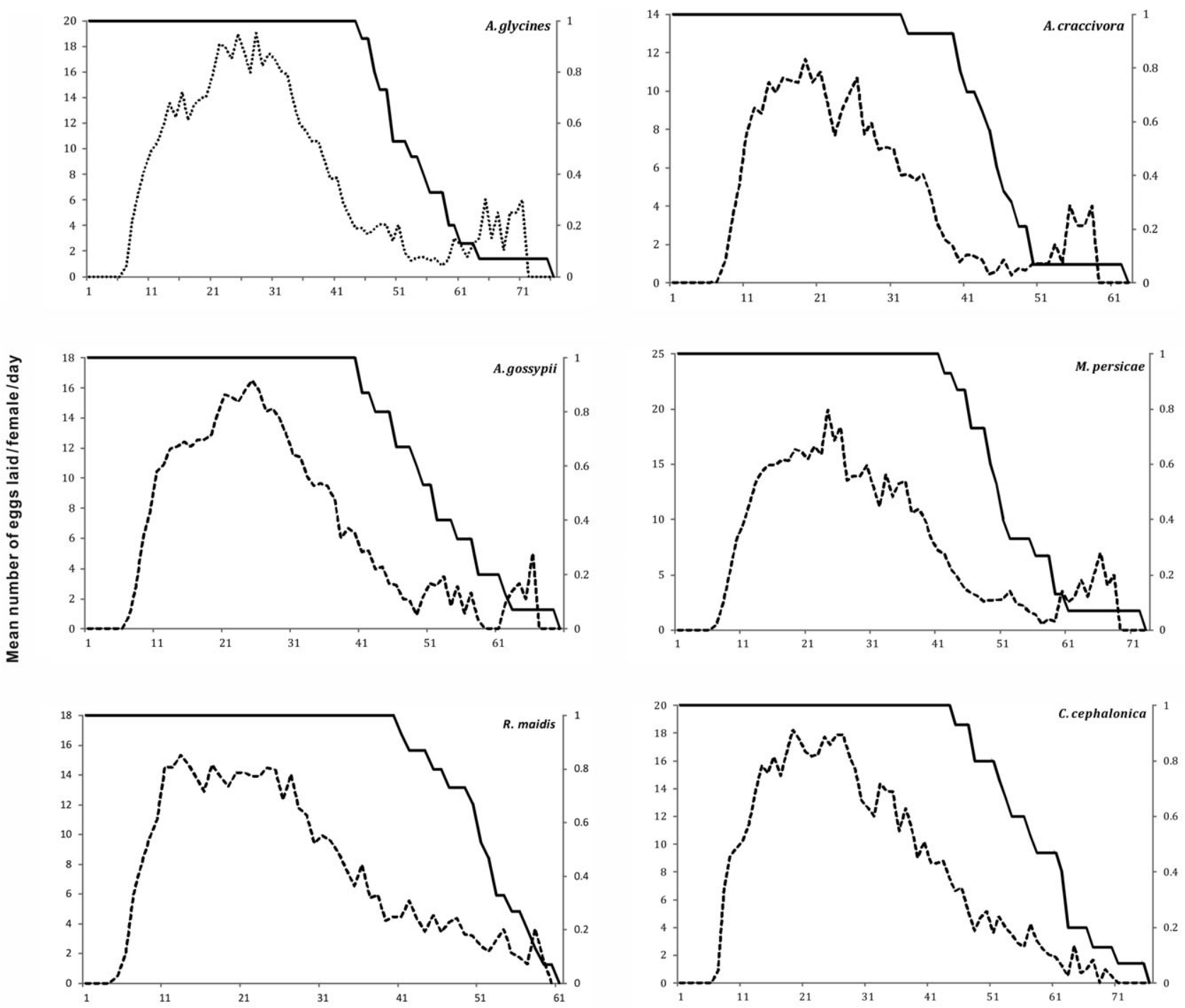

Adult longevity (days)

Fig. 1. Age-specific oviposition and proportion of $C$. sinica females surviving when reared on and fed different species of prey. Solid lines indicate survival and dotted lines mean number of eggs laid per day per female.

the pre-imaginal developmental period as well as adult longevity and fecundity of $C$. sinica provided with different species of prey. Generally, the $C$. sinica larvae that were reared on aphids had shorter pre-imaginal developmental periods and the adults lived longer and were more fecund except those reared on $A$. craccivora. This indicates that the species of prey is of paramount importance as part of a balanced source of food (Evans et al., 1999) to ensure the nutrients that enhance the pre-imaginal developmental period and the longevity and fecundity of the later stages of $C$. sinica. However, rearing $C$. sinica on range of different species of prey resulted in little variation, which might indicate that this predator is well adapted to this particular natural prey niche. The shorter pre-imaginal development period of larvae supplied with nymphs of $A$. gossypii and $R$. maidis compared to those supplied with $A$. glycines and $M$. persicae accords with the results of Obrycki et al. (1989), who report that larvae of Chrysopa oculata Say take less time to develop when reared on $R$. maidis. Above all, rearing $C$. sinica on $C$. cephalonica eggs resulted in larger females and higher pre-imaginal survival, fecundity and adult longevity compared with those reared on aphids, as previously recorded by Wang \& Nordlund (1994), Pappas et al. (2007) and Huang \& Enkegaard (2009), suggesting that eggs are very nutritious. However, the slightly lower fecundity and longevity of $C$. sinica reared on $A$. gossypii and $R$. maidis compared to those reared on $A$. glycines and M. persicae probably indicate variations among predators in their physiological responses to the different nutrient contents of prey. However, the pre-imaginal period of the ladybird Propylea quatuordecimpunctata is not affected by the type of prey, suggesting their nutrient content is sufficient to ensure survival and development (Kalushkov \& Hodek, 2005).

On the other hand, the significantly increased longevity, fecundity and percentage survival of $C$. sinica larvae reared on $A$. glycines and $M$. persicae might indi- 
cate adaptation to feeding on these aphids, which are widely abundant in the field. Further, there are also reports of shorter growth periods (pre-imaginal) in Chrysoperla rufilabris Burmeister larvae (Chen \& Liu, 2001) and Nineta flava Scopoli larvae (Principi \& Canard, 1984) reared on M. persicae.

In our study, the larvae reared on $A$. craccivora took longer to develop and the resultant adults were less fecund, which might be attributed to this aphid being a poor quality food. However, in contrast to our studies, Saminathan et al. (1999) report reduced pre-imaginal duration and increased fecundity for $C$. carnea reared on A. craccivora. This difference might be due to differences among the species in their nutritional requirements (ElArnaouty et al., 1996).

Finally, our study indicates that of all the prey tested the eggs of rice moth, C. cephalonica, are the most suitable food for the mass rearing of the $C$. sinica. In addition, this study indicates that the higher survival of $C$. sinica reared on moth eggs than on aphids might reflect the higher nutritional quality of eggs. It also shows that combinations of different food items could promote fecundity in mass rearing of $C$. sinica. However, further studies are required to evaluate the field performance of C. sinica in terms of feeding on aphids when they are mass reared on the eggs of Lepidoptera.

ACKNOWLEDGEMENTS. This research was partly supported by a special fund for Agro-scientific Research for the Public Interest (No. 200803032 and 201103002). N.H. Khuhro gratefully acknowledges the full scholarship support for his Ph.D. from China Scholarship Council (CSC).

\section{REFERENCES}

AnDow D.A. 1990: Characterization of predation on egg masses of Ostrinia nubilalis (Lepidoptera: Pyralidae). Ann. Entomol. Soc. Am. 83: 482-486.

Atlihan R., Kaydan B. \& ÖZgöKÇE M.S. 2004: Feeding activity and life history characteristics of the generalist predator, Chrysoperla carnea (Neuroptera: Chrysopidae) at different prey densities. J. Pest Sci. 77: 17-21.

Bansod R.S. \& SARode S.V. 2000: Influence of different prey species on biology of Chrysoperla carnea (Stephens). Shashpa 7: 21-24.

CHEN T.Y. \& LiU T.X. 2001: Relative consumption of three aphid species by the lacewing, Chrysoperla rufilabris, and effects on its development and survival. BioControl 46: 481-491.

Ding Y.Q. \& CHEN Y.P. 1986: Predation pattern of Chrysoperla (Chrysopa) sinica on cotton aphid and cotton bollworm. Chin. J. Biol. Control. 2: 97-102 [in Chinese].

Duelli P. 2001: Lacewings in field crops. In McEwen P.K., New T.R. \& Whittington A.E. (eds): Lacewings in the Crop Environment. Cambridge University Press, Cambridge, UK, pp. 158-171.

El-Arnaouty S.A., Ferran A. \& Beyssat-Arnaouty V. 1996: Food consumption by Chrysoperla carnea (Stephens) and Chrysoperla sinica (Tjeder) of natural and substitute prey: determination of feeding efficiency (Insecta: Neuroptera: Chrysopidae). In Canard M., Aspöck H. \& Mansel M.W. (eds): Pure and Applied Research in Neuropterology. Proceedings of the 5th International Symposium on Neuropterology, Cairo, 2-6 May 1994. Sacco, Toulouse, pp. 109-117.
El-Serafi H.A.K., Abdel-Salam A.H. \& Abdel-Bakey N.F. 2000: Effect of four aphid species on certain biological characteristics and life table parameters of Chrysoperla carnea (Stephens) and Chrysoperla septempunctata Wesmael (Neuroptera: Chrysopidae) under laboratory conditions. Pak. J. Biol. Sci. 3: 239-245.

Evans E.W., Stevenson A.T. \& Richard D.R. 1999: Essential versus alternative foods of insect predators: benefit of mixed diets. Oecologia 121: 107-112.

HAGEN K.S. \& TASSAN R.L. 1970: The influence of food wheast and related Saccharomyces fragilis yeast products on the fecundity of Chrysopa carnea (Neuroptera: Chrysopidae). Can. Entomol. 102: 806-811.

Huang N. \& EnkegaArd A. 2009: Predation capacity and prey preference of Chrysoperla carnea on Pieris brassicae. BioControl 55: 379-385.

Kalushrov P. \& Hodek I. 2005: The effects of six species of aphids on some life history parameters of the ladybird Propylea quatuordecimpunctata (Coleoptera: Coccinellidae). Eur. J. Entomol. 102: 449-452.

Kazemi F. \& Mehrnejad M.R. 2011: Seasonal occurrence and biological parameters of the common green lacewing predators of the common pistachio psylla, Agonoscena pistaciae (Hemiptera: Psylloidea). Eur. J. Entomol. 108: 63-70.

Kumar S. \& Singh S. 2001: Biocontrol potential of the predator, Chrysoperla carnea on mustard aphid under caged conditions. Ann. Plant Protect. Sci. 9: 306-308.

LeE K.S. \& LeE J.H. 2005: Rearing of Chrysopa pallens (Rambur) (Neuroptera: Chrysopidae) on artificial diet. Entomol. Res. 35: 183-188.

Li Y., Meissle M. \& Romeis J. 2008: Consumption of $B t$ maize pollen expressing Cry1 Ab or Cry3Bb1 does not harm adult green lacewings, Chrysoperla carnea (Neuroptera: Chrysopidae). PLoS ONE 3(8): e2909.

Liao H.T., Harris M.K., Gilstrap F.E. \& Mansour F. 1985: Impact of natural enemies on the blackmargined pecan aphid, Monellia caryella (Homoptera: Aphidae). Environ. Entomol. 14: $122-126$.

LIU T.X. \& ChEN T.Y. 2001: Effects of three aphid species (Homoptera: Aphididae) on development, survival and predation of Chrysoperla carnea (Neuroptera: Chrysopidae). Appl. Entomol. Zool. 36: 361-366.

López-Arroyo J.I., Tauber C.A. \& Tauber M.J. 1999: Effects of prey on survival, development, and reproduction of trashcarrying chrysopids (Neuroptera: Ceraeochrysa). Environ. Entomol. 28: 1183-1188.

Messina F.J. \& Sorenson S.M. 2001: Effectiveness of lacewing larvae in reducing Russian wheat aphid populations on susceptible and resistant wheat. Biol. Control 21: 19-26.

Obrycki J.J., Hamid M.N., Sajap A.S. \& Lewis L.C. 1989: Suitability of corn insect pest for development and survival of Chrysoperla carnea and Chrysoperla oculata (Neuroptera: Chrysopidae). Environ. Entomol. 18: 1126-1130.

Pappas M.L., Broufas G.D. \& Koveos D.S. 2007: Effects of various prey species on development, survival and reproduction of the predatory lacewing Dichochrysa prasina (Neuroptera: Chrysopidae). Biol. Control 43: 163-170.

PRINCIPI M.M. \& CANARD M. 1984: Feeding habits. in Canard M., Semeria Y. \& New T.R. (eds): Biology of Chrysopidae. Dr W. Junk, The Hague, pp. 76-92.

RAJABASKAR D. 2007: Stage preference and predatory potential of the bug Chrysoperla carnea against jasmine leaf webworm Nausinoe geometralis. J. Ecobiol. 19: 97-99. 
Ragsdale D.W., Landis D.A., Jacques B., Heimpel G.E. \& DesNEUX N. 2011: Ecology and management of the soybean aphid in North America. Annu. Rev. Entomol. 56: 375-379.

Rao C.N., Shivankar V.J. \& Shyam S. 2003: Predatory potential and development of the green lacewing (Mallada boninensis) on citrus leaf-miner (Phyllocnistis citrella). Indian $J$. Agric. Sci. 73: 60-61.

Saminathan V.R., Baskaran R.K.M. \& Mahadevan N.R. 1999: Biology and predatory potential of green lacewing (Chrysoperla carnea) (Neuroptera: Chrysopidae) on different insect hosts. Indian J. Agric. Sci. 69: 502-505.

SAS Institute 1988: SAS/STAT User's Guide, Release 6.03ed, SAS Institute, Cary, NC.

Senior L.J. \& McEwen P.K. 2001: The use of lacewings in biological control. In McEwen P.K., New T.R \& Whittington A.E. (eds): Lacewings in the Crop Environment. Cambridge University Press, Cambridge, pp. 296-302.

TAUber M.J. \& TAUBer C.A. 1983: Life history traits of Chrysopa carnea and Chrysopa rufilabris (Neuroptera: Chrysopidae): Influence of humidity. Ann. Entomol. Soc. Am. 76: 282-285.

Tauber M.J., Tauber C.A., DaAne K.M. \& Hagen K.S. 2000: Commercialization of predators: recent lessons from green lacewings (Neuroptera: Chrysopidae: Chrysoperla). Am. Entomol. 26: 26-38.

Uddin J., Holliday N.J. \& Mackay P.A. 2005: Rearing lacewings, Chrysoperla carnea and Chrysopa oculata (Neuroptera: Chrysopidae), on prepupae of alfalfa leafcutting bee, Megachile rotundata (Hymenoptera: Megachilidae). Proc. Entomol. Soc. Manitoba 61: 11-19.
Villenave J., Deutsch B., Lodé T. \& Rat-Morris E. 2006: Pollen preference of the Chrysoperla species (Neuroptera: Chrysopidae) occurring in the crop environment in western France. Eur. J. Entomol. 103: 771-777.

WANG R. \& NoRdLund D.A. 1994: Use of Chrysoperla spp. (Neuroptera: Chrysopidae) in augmentative release programmes for control of arthropod pests. Biocontrol News Inf. 15: $51-57$

WANG W.J. \& HE D.H. 2006: Research of the control role of three primary natural enemies to Tetranychus urticae (Koch). Chin. J. Agric. Sci. 27: 16-19 [in Chinese].

Xu Y., Mu J. \& Hu C. 1999: Research and utilization of Chrysoperla sinica. Entomol. Knowl. 36: 313-315 [in Chinese].

Zhang Y., Wu K.M., Wyckhuys K.A.G. \& Heimpel G.E. 2009: Trade-offs between flight and fecundity in the soybean aphid (Hemiptera: Aphididae). J. Econ. Entomol. 102: 133-138.

Zheng Y., Hagen K.S., DaAne K.M. \& Mittler T.E. 1993: Influence of larval dietary supply on the food consumption, food utilization efficiency, growth and development of lacewing Chrysoperla carnea. Entomol. Exp. Appl. 67: 1- 7.

ZHou W.R., WANG R. \& QIU S.B. 1991: Field studies on the survival of Chrysoperla sinica (Neuroptera: Chrysopidae) mass reared and inoculatively released in wheat fields in Northern China. Chin. J. Biol. Control. 7: 97-100.

Zhou W., Liu Z., Cheng W. \& Qiu S. 1981: Studies on the rearing of Chrysoperla sinica (Neuroptera: Chrysopidae) adults using dry dusty food. Plant Prot. 7: 2-3.

Received June 29, 2011; revised and accepted November 29, 2011 